\title{
Estimating the heat generation rate in a forced-aeration composting process by measuring temperature changes
}

\author{
Hirakazu SEKI ${ }^{\dagger}$, and Toshimitsu SHIJUKU \\ (College of Science and Engineering, Kanazawa University, Kanazawa, 920-1192, Japan)
}

\begin{abstract}
Knowing the rate of heat generation is useful when trying to understand the composting reaction rate. In this study, we conduct several experiments in composting with forced aeration, using a small, cylindrical reactor, and propose a practical method for estimating the heat generation rate. This simple method does not involve highly technical measurements but applies only the temperature measured in the compost materials to heat and moisture balance equations. The heat generation rates estimated using this method agree well with the results estimated from oxygen consumption rates. The amount of biologically decomposed organic matter also agrees well with the measured results. Therefore, the validity of this method is confirmed. Although it is necessary to confirm that this method is applicable irrespective of the type of organic compound, it is useful as a basic experimental procedure to examine the decomposition characteristics of the targeted organic wastes.
\end{abstract}

Key words: Composting, Heat balance, Moisture balance, Oxygen concentration, Reaction heat with organic decomposition.

\section{Introduction}

Composting is a method of waste recycling and is an agricultural application of unutilized resources (e.g., Yukishitsusigenka-suishinkaigi, 1997; Kimura, 2003). Although any type of organic material can be used for composting, it is difficult to present a detailed mathematical model for the composting process, because it involves a complicated phenomenon, that is, a microbial chemical reaction. As compost is a dispersed medium comprising of solid, liquid, and gas phases, an exact prediction of the reaction rate based on a representative elementary volume (REV) scale (Bear and Bachmat, 1991) is important to aid in the design of composting equipment from an engineering viewpoint. With the rapid development of gene detection techniques, microbial group analysis of composting has recently come to be conducted (e.g., Inoue, 2003; Tang et al., 2007; Wakase et al., 2008). Nevertheless, information on the diversification of reaction materials and microbes is insufficient, and so it is difficult to

Received; May 2, 2011.

Accepted; December 6, 2011.

†Corresponding Author: seki@t.kanazawa-u.ac.jp quantitatively estimate the overall reaction rate on a REV scale. Therefore, indirect methods based on temporal and spatial variations of state variables, such as temperature and concentration, might be effective for understanding the overall reaction property in a REV. The rate of heat generation in a reaction vessel is requisite information to obtain the reaction rate.

In a laboratory-scale, non-stirred reaction vessel, the conditions of temperature and concentration vary spatially. Therefore, to obtain the rate of heat generation, it is appropriate to use an estimation method that applies the observed temperature in the reaction vessel to a model equation.

Thus far, there have been several studies conducted on heat balance models for composting processes, such as Finger et al. (1976), Nakasaki et al. (1987), Kaiser (1996), Stombaugh and Nokes (1996), Das and Keener (1997), VanderGheynst et al. (1997), and Seki (2002). However, only two of these studies have been published for estimations based on the heat balance method. One is a back-calculation method using the analytical solution of the heat conduction equation for a non-aerated static composting process (Seki and Komori, 1983, 1984), and the other is based on the results of experiments conducted in a very small-scale 
reactor (Iwabuchi and Kimura, 1994). Since practical composting processes typically involve aeration, air convection must be considered, and a method using the model equation corresponding to the air flow is therefore required. Although the model proposed by Iwabuchi and Kimura (1994) considers air entering and leaving, it is only applicable to a small reaction vessel with a volume of $1 \mathrm{l}$. Moreover, the model assumes that temperatures are spatially uniform and does not consider spatial temperature variations. In general, spatial non-uniformity of temperature and material concentration is inevitable with an increase in the volume of the compost container.

We conducted composting experiments using a small cylindrical vessel with forced aeration. Based on these experiments, we proposed a method for estimating the heat generation rate by applying the temperature measured at any point within the compost container to heat balance equations for a finite difference representation. Because this method deals with composting under condition of forced aeration, it will be worthwhile and useful to apply it to the actual system design of the composting process.

\section{Theory}

\subsection{Heat and moisture balance equations}

As pointed out in the introduction, the temperature and concentration of compost materials are spatially non-uniform. In this case, composting phenomena are non-linear with respect to temperature, and so it is incorrect to express the spatial average heat generation rate or reaction rate as a function of spatial average temperature and concentration. Therefore, we derived spatially differential-type shell balance equations for heat and moisture, and obtained the spatially different heat generation rate by applying heat transfer analysis.

To derive a heat balance equation for a compost container, we set the following assumptions:

1) The temperature of the moist solid phase - both solid and liquid parts, is equal to that of the gaseous phase because of a very low gas flow rate.

2) The gas flow rate through the compost bed is constant.

3) Physical properties (heat capacity, thermal conductivity, and density) of the mixed compost materials do not vary.

4) Spatial variation of the physical and chemical properties of the mixed compost materials in the horizontal direction $r$ is small compared to the variation in the vertical direction $z$.

Under the above assumptions, a shell balance of thermal energy within a small increment of $z, \Delta z$, during an infinitesimal time increment $\Delta t$ is shown in Fig. 1. In the figure, the calculation uses the temperature of the mixed compost materials $(T)$; the atmospheric air temperature $\left(T_{a}\right)$; the inner radius of the compost container $\left(R_{v}\right)$; the specific heat of the mixed compost materials $(C)$; the density of the mixed compost materials $(\rho)$; the effective thermal conductivity of the mixed compost materials $(K)$; the specific heat of the ambient air $\left(C_{a}\right)$; the density of the aerated air $\left(\rho_{\mathrm{a}}\right)$; the airflow rate averaged over the cross sectional area of the compost bed $(u)$; the overall heat transfer coefficient at the side wall of the compost container $(U)$; and the apparent rate of heat generation $\left(R_{H}\right)$, where $R_{H}$ $=$ the actual heat generation rate-the heat consumption rate with water evaporation. Following the law of conservation of energy, we obtain the following:

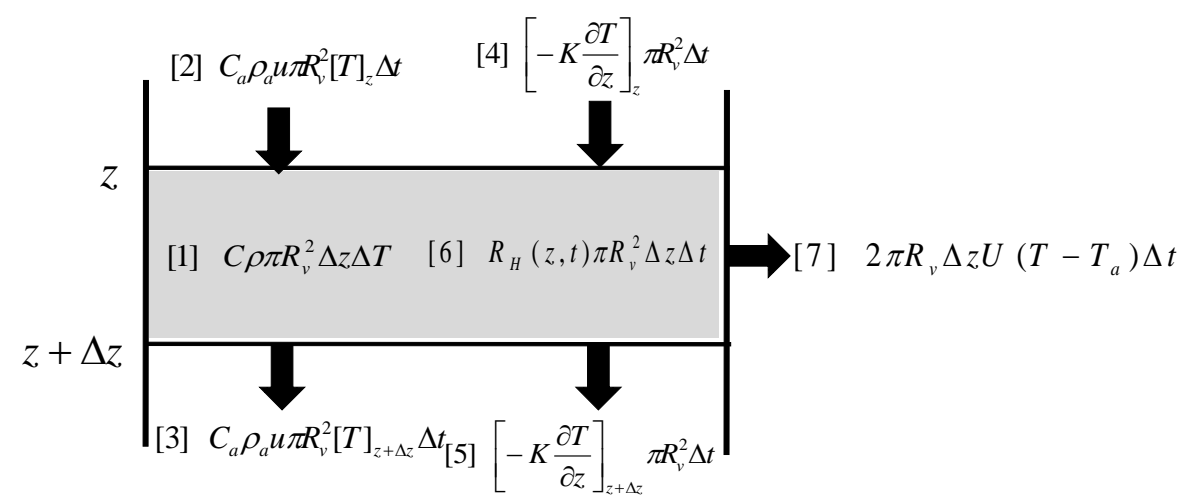

Fig. 1. Shell balance of thermal energy within a small increment $\Delta z$. 
$[1]=[2]+[4]-[3]-[5]+[6]+[7]$,

where terms [1]-[7] are as follows:

[1]: accumulation

$C \rho \pi R_{v}^{2} \Delta z \Delta T$

[2]: flow-in by advection

$C_{a} \rho_{a} u \pi R_{v}^{2}[T]_{z} \Delta t$

[3]: flow-out by advection

$C_{a} \rho_{a} u \pi R_{v}^{2}[T]_{z+\Delta z} \Delta t$

[4]: flow-in by heat conduction $\quad\left(-K \frac{\partial T}{\partial z}\right)_{z} \pi R_{v}{ }^{2} \Delta t$

[5]: flow-out by heat conduction $\left(-K \frac{\partial T}{\partial z}\right)_{z+\Delta z} \pi R_{v}{ }^{2} \Delta t$

[6]: heat generation

$$
R_{H} \pi R_{v}{ }^{2} \Delta z \Delta t
$$

[7]: heat loss from the side wall of the compost container

$2 \pi R_{v} \Delta z U\left(T-T_{a}\right) \Delta t$.

Substituting each term in the above relationship and dividing it by $\pi R_{v}{ }^{2} \Delta z \Delta t$, the following basic heat transfer equation is obtained as the increments $\Delta z$ and $\Delta t$ approach zero:

$$
C \rho \frac{\partial T}{\partial t}+C_{a} \rho_{a} u \frac{\partial T}{\partial z}=K \frac{\partial^{2} T}{\partial z^{2}}-\frac{2 U}{R_{v}}\left(T-T_{a}\right)+R_{H}(z, t)
$$

where $R_{H}$ is given by the equation:

$$
R_{H}=Q_{H}-E_{H} L
$$

which uses the actual heat generation rate $\left(Q_{H}\right)$, the water evaporation rate in the vessel $\left(E_{H}\right)$, and the latent heat of water evaporation $(L)$.

The exact details of the boundary conditions for heat and mass transfer are somewhat subtle for a tubular reactor (Himmelblau and Bischoff, 1968) such as the compost container used in our experiments. Therefore, instead of setting the boundary conditions at both ends of the compost container, we set the conditions for the continuously measured temperature results at internal points that were $0.03 \mathrm{~m}$ away from both ends of the container. These measured temperature results vary with time.

On the other hand, Fig. 2 shows a shell balance of moisture in an elementary volume within the time interval $\Delta t$. In the figure, the calculation uses the free air space in mixed compost materials $(\varepsilon)$, molar fraction of moisture in free air space $\left(X_{H}\right)$, water vapor diffusivity in free air space $\left(D_{H}\right)$, and the volume-based moisture evaporation rate $\left(E_{v H}\right)$.

Following the law of conservation of mass, we obtain the following:

$[1]=[2]+[4]-[3]-[5]+[6]$,

where terms [1]-[6] are as follows:

[1]: accumulation

$\varepsilon \Delta X_{H} \pi R_{v}^{2} \Delta z$

[2]: flow-in by advection

$u \pi R_{v}^{2}\left[X_{H}\right]_{z} \Delta t$

[3]: flow-out by advection

$u \pi R_{v}^{2}\left[X_{H}\right]_{z+\Delta z} \Delta t$

[4]: flow-in by diffusion

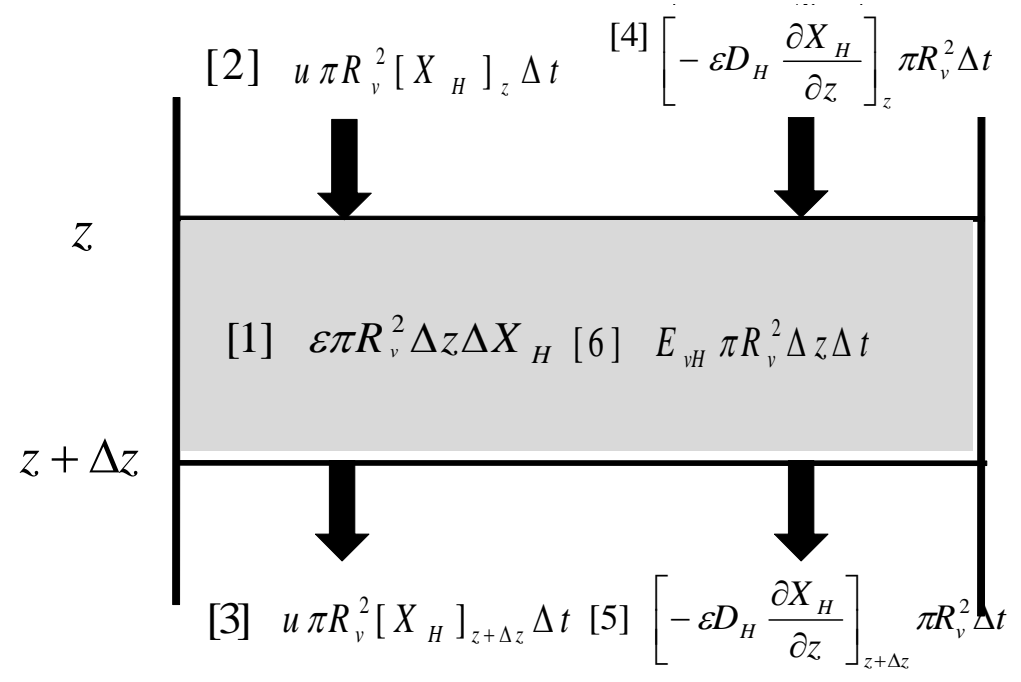

Fig. 2. Shell balance of moisture within a small increment $\Delta z$. 
[5]: flow-out by diffusion

$$
\left(-\varepsilon D_{H} \frac{\partial X_{H}}{\partial z}\right)_{z+\Delta z} \pi R_{v}^{2} \Delta t
$$

[6]: internal generation

$$
E_{v H} \pi R_{v}^{2} \Delta z \Delta t \text {. }
$$

Substituting each term in the above relationship, dividing it by $\pi R_{v}{ }^{2} \Delta z \Delta t$, the following basic water vapor transfer equation is obtained as the increments $\Delta z$ and $\Delta t$ approach zero:

$$
\varepsilon \frac{\partial X_{H}}{\partial t}=-u \frac{\partial X_{H}}{\partial z}+\varepsilon D_{H} \frac{\partial^{2} X_{H}}{\partial z^{2}}+E_{v H}
$$

\subsection{Derivation of the equation used to estimate the heat generation rate at any point in the vessel}

Considering that pores of free air space in the mixed compost materials packed in the vessel are small and the air velocity is slow, we set the following assumptions:

1) The water vapor in the pores and the water in contact with this water vapor are in equilibrium.

2) Relative humidity is more than 0.94 in the microbial growth stage (Fujita, 1993), which is approximately equal to the maximum value of 1 , so that the activity of the water in contact with the water vapor can be taken as 1 .

According to the above assumptions, the volumebased water evaporation rate $E_{v H}$ is a function of $T$ alone and is formulated using the procedure mentioned as follows:

First, the activity of the components of the ideal gas is numerically equal to the partial pressure expressed in standard atmosphere (atm) units (Uematsu et al., 1982), and the partial pressure is equal to the molar fraction because the total pressure is $1 \mathrm{~atm}$ in this study. Therefore, the equilibrium constant between the liquid water in the mixed compost materials and the neighboring water vapor $K_{e q}$ is given as:

$$
K_{\text {eq }}=\frac{\text { activity of water vapor }}{\text { activity of liquid water }}=\frac{X_{H}}{1}=X_{H}
$$

The latent heat of water evaporation $L$ is $2450 \mathrm{Jg}^{-1}$ at $20^{\circ} \mathrm{C}$ and $2360 \mathrm{Jg}^{-1}$ at $60^{\circ} \mathrm{C}$, that is, it has a maximum difference of only $4 \%$. Therefore, if $L$ is regarded to be constant, that is, independent of the temperature variation of the experiment, then $K_{e q}$ is dependent only on temperature and is given as:

$$
K_{e q}(T)=K_{0} e^{-\frac{\Delta H_{V}^{0}}{R T}}=X_{H}
$$

where $\Delta H_{v}{ }^{0}(=L \times$ molar mass of water $)$ represents the molar latent heat of water evaporation $\left(4.33 \times 10^{6}\right.$ $\left.\mathrm{Jmol}^{-1}\right), R$ represents the gas constant $\left(8.314 \mathrm{Jmol}^{-1} \mathrm{~K}^{-1}\right.$ ) and $K_{0}$ is a constant $\left(1.22 \times 10^{6}[-]\right)$. This equation is obtained by integrating the van't Hoff equation (Atkins and de Paula, 2006).

Substituting Eq. (5) in Eq. (3) and rearranging the resulting equation, we get the following equation for $E_{v H}$ :

$$
\begin{aligned}
E_{v H}= & \varepsilon\left(\frac{\Delta H_{v}^{0}}{R T^{2}} K_{e q}\right) \\
& {\left[\frac{\partial T}{\partial t}+\left\{\frac{u}{\varepsilon}-D_{H}\left(\frac{\Delta H_{v}^{0}}{R T^{2}}-\frac{2}{T}\right) \frac{\partial T}{\partial z}\right\} \frac{\partial T}{\partial z}-D_{H} \frac{\partial^{2} T}{\partial z^{2}}\right] }
\end{aligned}
$$

The product of the saturated water vapor density $\rho_{v s}(T)\left\{(273 / T)\left(M_{H} / 22.4\right)\right\}$ and $E_{v H}$ gives the massbased water evaporation rate $E_{H}\left[\mathrm{kgm}^{-3} \mathrm{~h}^{-1}\right]$ as shown below:

$$
\begin{aligned}
E_{H}= & \rho_{v s}(T) E_{v H}=\frac{273}{T} \frac{M_{H}}{22.4} \varepsilon\left(\frac{\Delta H_{v}^{0}}{R T^{2}} K_{e q}\right) \\
& {\left[\frac{\partial T}{\partial t}+\left\{\frac{u}{\varepsilon}-D_{H}\left(\frac{\Delta H_{v}^{0}}{R T^{2}}-\frac{2}{T}\right) \frac{\partial T}{\partial z}\right\} \frac{\partial T}{\partial z}-D_{H} \frac{\partial^{2} T}{\partial z^{2}}\right] }
\end{aligned}
$$

Substituting Eq. (7) in Eq. (1) and rearranging the obtained result, we get the equation for the actual heat generation rate $Q_{H}$, which is composed of only temperature $T$ and its derivatives $\partial T / \partial t, \partial T / \partial z$, and $\partial^{2} T / \partial z^{2}$,

$$
\begin{aligned}
Q_{H}= & \left\{C \rho+L \frac{273}{T} \frac{M_{H}}{22.4} \varepsilon\left(\frac{\Delta H_{v}^{0}}{R T^{2}} K_{e q}\right)\right\} \frac{\partial T}{\partial t} \\
& +\left[C_{a} \rho_{a} u+L \frac{273}{T} \frac{M_{H}}{22.4} \varepsilon\left(\frac{\Delta H_{v}^{0}}{R T^{2}} K_{e q}\right)\right. \\
& \left.\left\{\frac{u}{\varepsilon}-D_{H}\left(\frac{\Delta H_{v}^{0}}{R T^{2}}-\frac{2}{T}\right) \frac{\partial T}{\partial z}\right\}\right] \frac{\partial T}{\partial z} \\
& -\left\{K+L \frac{273}{T} \frac{M_{H}}{22.4} \varepsilon\left(\frac{\Delta H_{v}^{0}}{R T^{2}} K_{e q}\right) D_{H}\right\} \\
& \frac{\partial^{2} T}{\partial z^{2}}+\frac{2 U}{R_{v}}\left(T-T_{a}\right)
\end{aligned}
$$


The derivatives $(\partial T / \partial t)_{i}$, $(\partial T / \partial z)_{i}$, and $\left(\partial^{2} T / \partial z^{2}\right)_{i}$ are expressed by the finite difference representation as follows:

$$
\begin{aligned}
& \left(\frac{\partial T}{\partial t}\right)_{i}=\frac{T^{\prime}(i)-T(i)}{\Delta t} \\
& \left(\frac{\partial T}{\partial z}\right)_{i}=\frac{T(i+1)-T(i-1)}{2 \Delta z} \\
& \left(\frac{\partial^{2} T}{\partial z^{2}}\right)_{i}=\frac{T(i+1)-2 T(i)+T(i-1)}{(\Delta z)^{2}}
\end{aligned}
$$

where $T(i)$ and $T^{\prime}(i)$ indicate the measured temperature at the point $i(1,2,3, \ldots 10$, interval $\Delta z)$ at time $t$ and $t+\Delta t$, respectively.

By substituting the abovementioned measured temperature results in Eq. (8), we obtain the value of the rate of heat generation $Q_{H}$ at any point $i$ from the initial situation.

\section{Experiment}

\subsection{Raw materials and thermophysical properties of mixed compost materials}

In this experiment, the main substance in the organic materials mixture used for composting was rice bran. Chicken manure and sawdust were used for conditioning the carbon/nitrogen $(\mathrm{C} / \mathrm{N})$ ratio and water content. Table 1 shows the mixing ratio, $\mathrm{C}$ and $\mathrm{N}$ contents, and the moisture content (wet mass base) of the raw materials. The tip size of sawdust was adjusted to $\leq 2 \mathrm{~mm}$ by sieving to achieve a good mixing condition of the raw materials.

The values of the $\mathrm{C} / \mathrm{N}$ ratio and moisture content were set to about 30 and $60 \%$, respectively, which are known to be optimal for composting (Kubota and Hosono, 1977), and the density was set to $500 \mathrm{kgm}^{-3}$. Table 2 shows the values of moisture content, $\mathrm{C}$ and $\mathrm{N}$ contents, and $\mathrm{C} / \mathrm{N}$ ratio for the mixed compost materials. The free air space $\varepsilon$ of the mixed compost materials was 0.57 , which was large enough for aeration. Thermal conductivity was $2.1 \mathrm{~kJ} \mathrm{~m}^{-1} \mathrm{~h}^{-1} \mathrm{~K}^{-1}$, which had been measured by the steady-state condition method. Specific heat was obtained following an empirical equation correlated to the moisture content (Seki and Komori, 1983).

\subsection{Experimental apparatus and method}

The compost container is an acrylic resin vessel, $0.022 \mathrm{~m}^{3}$ in volume, with an inner diameter of $200 \mathrm{~mm}$, height of $690 \mathrm{~mm}$, and thickness of $10 \mathrm{~mm}$. The container was insulated with 100-mm-thick styrofoam resin. To measure the temperature in the vessel and the air at the entrance and exit, $10 \mathrm{Cu}$-Co thermocouples were set for the compost materials and two for air temperature, as shown in Fig. 3. Temperature data were recorded by a data-logger (MX100, Yokogawa Electric Co.) every $30 \mathrm{~min}$. At the bottom of the container, we set an inverted siphon-type condenser to recover the condensed water during the experiment and to obtain a uniform moisture profile in the vertical direction. Nevertheless, values of moisture content are significantly different for the top and bottom parts of the compost vessel, as shown in Table 2. However, moisture variation is not so large, and for the main part of the mixed compost materials in the vessel (except around both ends of the vessel), it seems to be spatially uniform compared to the results obtained under the inverse air-flow condition in this experiment (Seki et al., 2008).

First, the flow rate of the compressed air from a compressor is controlled through the mass flow controller, and then the compressed air is supplied to the air chamber set at the top of the container. The air flows down the container until it reaches the bottom and flows out through the vinyl plastic pipe and the condenser where the vapor is condensed and removed after measurement. The oxygen concentration of the dry gas is automatically measured by an oxygen meter (OXYMAN, OM25MF10, Taiei Electric Co.) and finally exhausted to the open air.

Because the optimum air flow rate is known to be 50 $\operatorname{lmin}^{-1}$ per unit volume $\left(\mathrm{m}^{3}\right)$ of compost container (Izawa, 1989), we set it as $1.08 \mathrm{lmin}^{-1}$ in this experi

Table 1. Moisture, carbon, and nitrogen contents, and $\mathrm{C} / \mathrm{N}$ ratio of raw materials

\begin{tabular}{lccccc}
\hline & $\begin{array}{c}\text { Mixing ratio } \\
\mathrm{w}[\mathrm{wt} \%]\end{array}$ & $\begin{array}{c}\text { Moisture content } \\
\mathrm{w}[\mathrm{wt} \%]\end{array}$ & $\begin{array}{c}\text { Carbon content } \\
\mathrm{C}\left[\mathrm{kg}^{-} \mathrm{C} \mathrm{kg}{ }^{-1}-\mathrm{DS}\right]\end{array}$ & $\begin{array}{c}\text { Nitrogen content } \\
\mathrm{N}\left[\mathrm{kg}^{-\mathrm{C} \mathrm{kg}} \mathrm{kg}^{-1} \text {-DS] }\right.\end{array}$ & $\begin{array}{c}\mathrm{C} / \mathrm{N} \text { ratio } \\
\mathrm{C} / \mathrm{N} \mathrm{[-]}\end{array}$ \\
\hline Rice bran & 24 & 13.4 & 0.455 & 0.0283 & 16.1 \\
Chicken manure & 24 & 12.5 & 0.327 & 0.0242 & 13.5 \\
Sawdust & 52 & 9.5 & 0.455 & 0.0031 & 147.0 \\
\hline
\end{tabular}


Table 2. Moisture, carbon, and nitrogen contents, and $\mathrm{C} / \mathrm{N}$ ratio of mixed compost materials at the initial and final conditions.

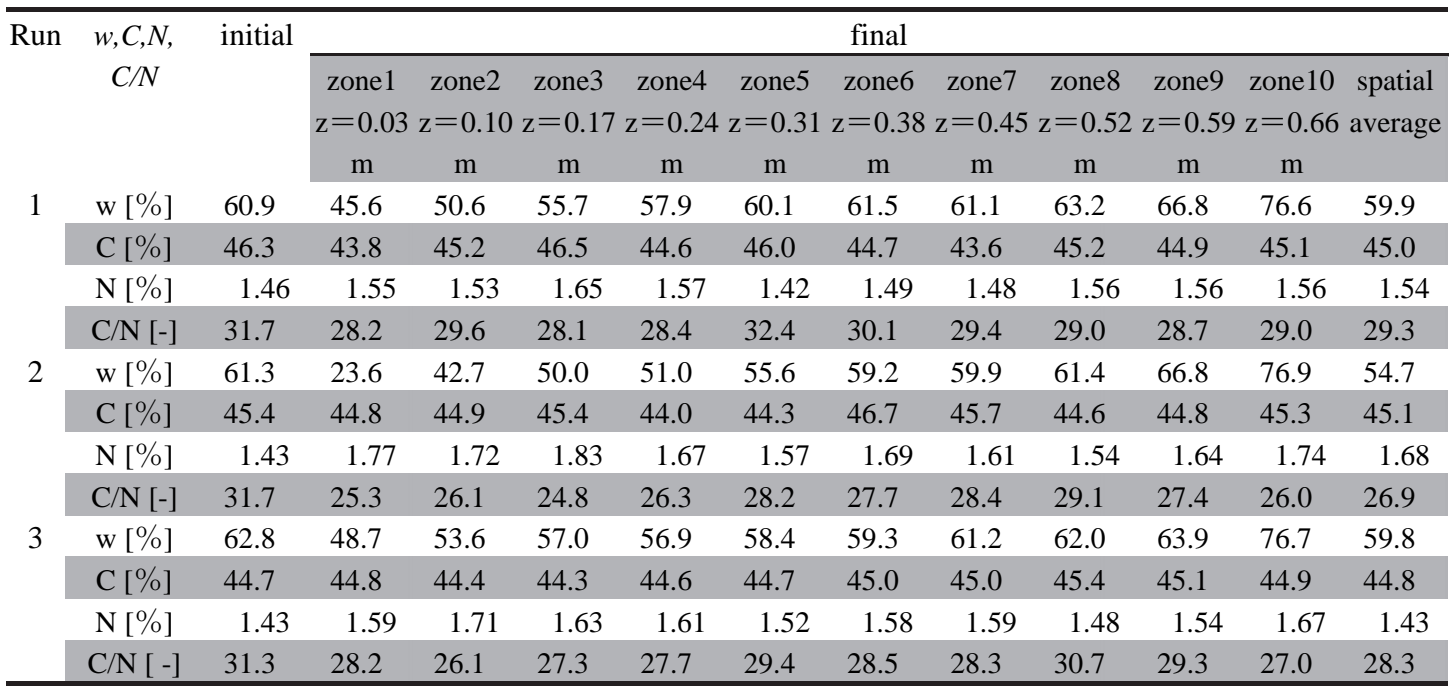

unit: $\mathrm{mm}$

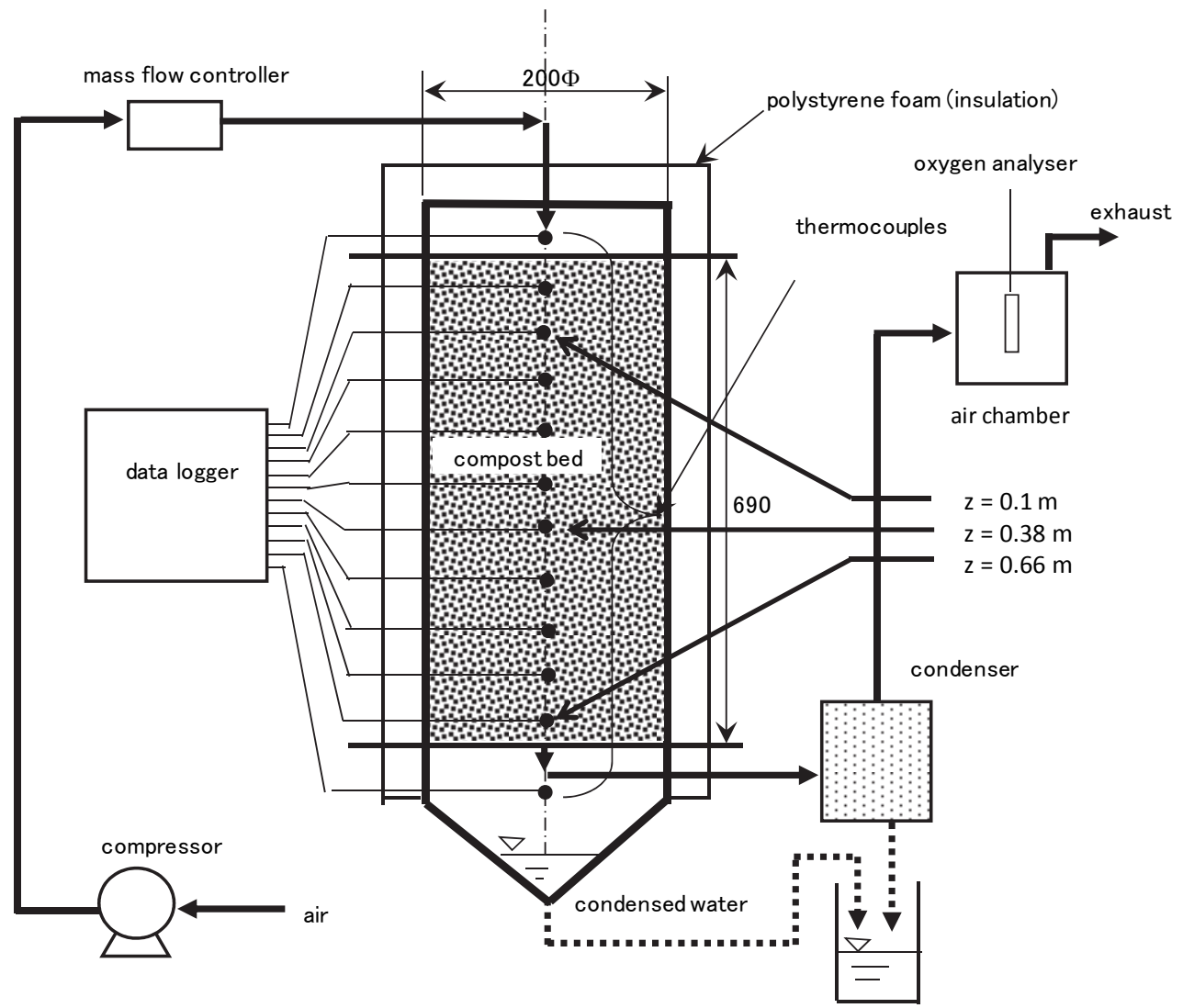

Fig. 3. Experimental apparatus where the points $z=0.1,0.38$, and $0.66 \mathrm{~m}$ are representatives for the top, middle, and bottom region, respectively. 
Table 3. Physical properties of air and water vapor and operating conditions for the experiments.

\begin{tabular}{lcll}
\hline & Symbol & value & \multicolumn{1}{c}{ unit } \\
\hline Heat capacity of air & $C_{a}$ & 1.0 & $\mathrm{~kJ} \mathrm{~kg}^{-1} \mathrm{~K}^{-1}$ \\
Inner radius of sample container & $R_{v}$ & 0.1 & $\mathrm{~m}$ \\
Mass of unit mol of water & $M_{H}$ & 0.018 & $\mathrm{~kg} \mathrm{~mol}^{-1}$ \\
Water vapor diffusivity in the air & $D_{H}$ & 0.066 & $\mathrm{~m}^{2} \mathrm{~h}^{-1}$ \\
Density of air & $\rho_{a}$ & 1.1 & $\mathrm{~kg} \mathrm{~m}^{-3}$ \\
Cross sectional average velocity of air & $u$ & 2.06 & $\mathrm{~m} \mathrm{~h}^{-1}$ \\
Overall heat transfer coefficient on the side wall of the container & $U$ & 1.47 & $\mathrm{~kJ} \mathrm{~m}^{-2} \mathrm{~h}^{-1} \mathrm{~K}^{-1}$ \\
\hline
\end{tabular}

ment, considering the container volume to be $0.022 \mathrm{~m}^{3}$.

After packing the compost materials in the container, we left the container undisturbed for $24 \mathrm{~h}$, which is the induction period for the completion of microbial growth, after which aeration was started. Table 3 shows the physical properties of air, water vapor, and operating conditions used in the experiments. The value of $U$ was obtained by considering thermal conductivity and thickness of the styrofoam resin covering the compost container.

Factors used for the measurements include temperature, oxygen concentration, and the total weight. Oxygen concentration at the exit of the air chamber, as shown in Fig. 3, was automatically measured and recorded every minute. The total weight of the compost container was measured every hour by setting the sample container on a balance. When the oxygen concentration reached over $20 \%$, that is, when the consumption rate became very small, we concluded the experiment.

The experiment was conducted three times (runs 13) in order to confirm the repeatability. As already described in Table 1, the raw material content and the moisture content are the same for all runs. One difference in the conditions of these experimental runs is the season in which each experiment was conducted, that is, run 1 was conducted in February, 2010, and runs 2 and 3 were conducted in November, 2010.

Moisture content and $\mathrm{C} / \mathrm{N}$ ratio were measured before and after each experiment. Dividing the mixed compost materials into 10 parts on the basis of the temperature measuring points, we selected three pieces of compost material for each part and measured the properties of moisture, carbon and nitrogen contents. The experimental results for the properties are the average of the three sets of data.

\section{Results and Discussion}

\subsection{Temperature in the container}

Figure 4 shows the change in the total mass of mixed compost materials in the container over time. In all runs, this change remained almost constant after $150 \mathrm{~h}$. This fact suggests that the decomposition of easily biodegradable organic materials (the first stage of composting) had completed by then.

Figure 5 shows the experimental results concerning the material temperature. The time lag before starting the initial temperature increase was $0 \mathrm{~h}$ for run $1,10 \mathrm{~h}$ for run 2 , and $5 \mathrm{~h}$ for run 3 . Subsequently, for all runs there was a tendency for the temperature increase to temporarily stop at around $45^{\circ} \mathrm{C}$, increase again after 5$10 \mathrm{~h}$, and reach a maximum of $60-65^{\circ} \mathrm{C}$. For runs 2 and 3 , temperatures increased further to reach around $70^{\circ} \mathrm{C}$. High temperature periods, during which the temperature was higher than $50^{\circ} \mathrm{C}$, lasted $100 \mathrm{~h}$ for run $1,80 \mathrm{~h}$ for run 2 , and $70 \mathrm{~h}$ for run 3 . Subsequently, temperatures gradually decreased to room level.

Although all the experiments had started $24 \mathrm{~h}$ after packing the mixed compost materials, there was a difference in the time lag before the phases where temperatures began to increase, as described above. This

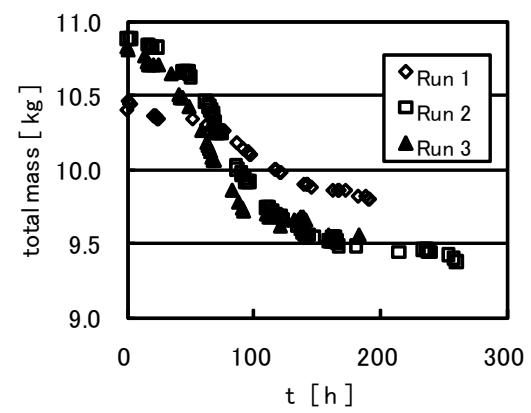

Fig. 4. Change in the total mass of mixed compost materials in the container with time. 

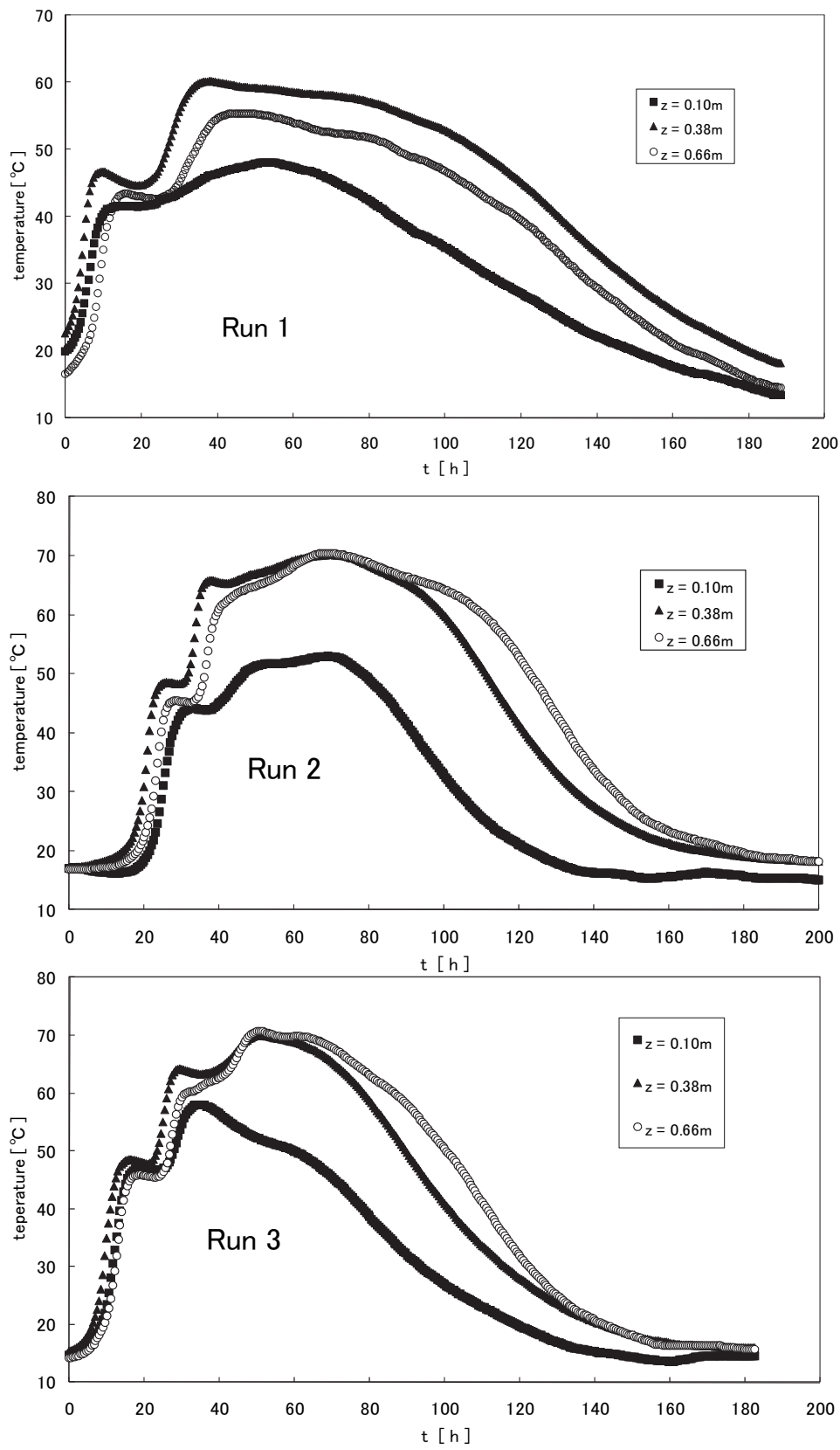

Fig. 5. Experimental temperature in the compost materials with time where the points $z=0.1,0.38$, and $0.66 \mathrm{~m}$ are representatives for the top, middle, and bottom region, respectively.

result suggests that the time interval for naturalization should be treated as a stochastic phenomenon. The temperature gradually changes from the top of the container at the air entrance $(z=0.1 \mathrm{~m})$ toward the bottom of the container $(z=0.66 \mathrm{~m})$, and this spatial temperature distribution causes a variation in reaction rates. Microbes are expected to be more active near the air entrance because of the high temperature; however, an increase in temperature was suppressed by water evaporation. Toward the bottom region, the temperature increased due to heat accumulation, and therefore made the microbial reaction become active. 
The duration for the microbial shift from the mesophilic to thermophilic temperature conditions and the duration for the temperature shift are almost the same for all the experimental runs because the content of the raw materials was the same for all runs.

\subsection{Oxygen concentration}

Figure 6 shows a plot of the measured oxygen con- centration in the air chamber as a function of time. It was found that oxygen concentration decreased when the rate of temperature increase was high, and so the oxygen consumption rate was coupled with the composting reaction rate. The minimum value of oxygen concentration is about $5 \%$ (6\% for run $1,6 \%$ for run 2 , and $4.5 \%$ for run 3 ). As the minimum requirement
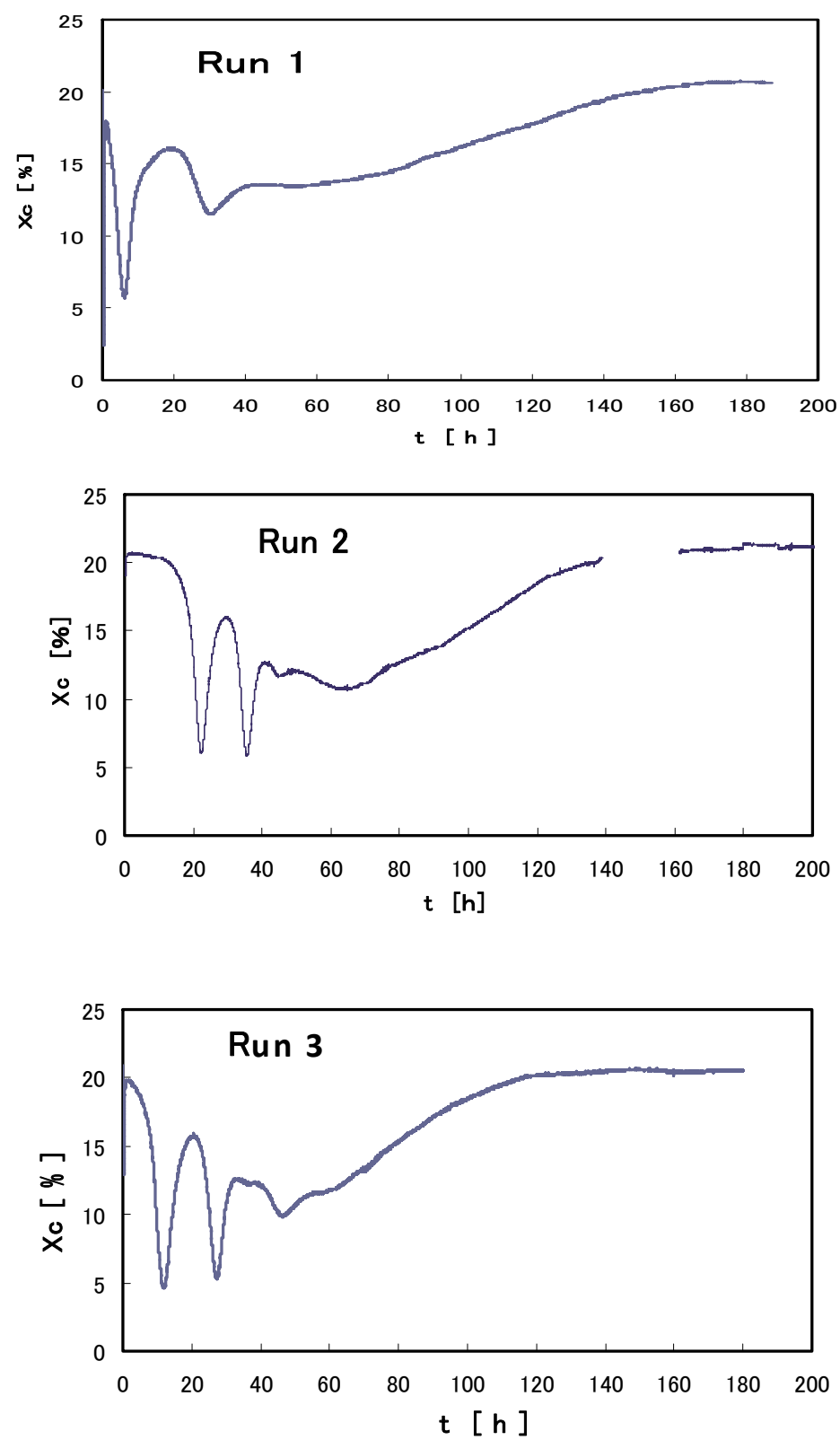

Fig. 6. Measured oxygen concentration in the air chamber over time where data is missing between $t=140-160 \mathrm{~h}$ for run 2 because of temporary breakdown of oxygen meter. 
of the oxygen concentration is $10 \%$ according to Fujita (1993), the aerobic condition was not satisfied during the period when the oxygen concentration was less than the minimum value. In other words, aerobic microbes such as bacteria, actinomycetes, and fungi were very active and the oxygen consumption rate was very high during this period. For almost all periods, except the abovementioned, the aerobic condition was satisfied.

\subsection{Heat generation rate $Q_{H}$ 1) Validity of the obtained results}

Figure 7 shows the calculated results of $Q_{H}$ using Eq. (8). In the calculation, we assumed that the values of density and the specific heat of the compost materials at any position vary with time from the initial to the final stage, accompanied by a linear temporal change of the moisture content. The time interval $\Delta t$ for estimating $Q_{H}$ by Eq. (8) was set to be $0.5 \mathrm{~h}$. This value of $\Delta t$ is as small as about 400-500th part of the duration of each experiment (190h for Run 1, 260h for Run 2, $180 \mathrm{~h}$ for Run 3), such that the change in the physical properties within $\Delta t$ was very small, and the estimated results of $Q_{H}$ would be close to its real value.

First, we compare the calculated values with those that were estimated from the measured oxygen concentration. It is known that $Q_{H}$ is proportional to the oxygen consumption rate $R_{X}$ under the aerobic condition, as follows (Fujita, 1993):

$$
\begin{aligned}
& Q_{H}=a R_{X} \\
& R_{X}\left[\mathrm{~kg}-\mathrm{O}_{2} /\left(\mathrm{m}^{3} \mathrm{~h}\right)\right]=\frac{P_{0} M}{R T_{\text {ain }}} u \frac{\left(X_{\text {in }}-X_{\text {ou }}\right)}{l}
\end{aligned}
$$

where $P_{0}$ indicates total pressure $\left(1.0 \times 10^{5} \mathrm{~Pa}\right), R$ indicates the gas constant $\left(8.314 \mathrm{~J} \mathrm{~mol}^{-1} \mathrm{~K}^{-1}\right), a$ indicates the proportionality constant $\left(14000 \mathrm{~kJ} \mathrm{~kg}^{-1}\right), M$ indicates the molar mass of oxygen $\left(0.032 \mathrm{~kg} \mathrm{~mol}^{-1}\right)$, $X_{\text {in }}$ indicates the mole fraction of oxygen at the inlet of the compost bed (0.21), $X_{\text {ou }}$ indicates the mole fraction of oxygen at the outlet of the compost bed, $T_{\text {ain }}$ indicates the air temperature at the inlet of the compost bed, and $l$ indicates the height of the compost bed $(0.69 \mathrm{~m})$. Therefore, if the heat generation rate obtained from the measured values of temperature is valid, its average over the vessel must be proportional to the oxygen consumption rate. To determine the feasibility of the above relationship, we consider the validity of the results of the heat generation rate obtained by this method.

As described in section 3.2, we measured the oxygen concentration in the air chamber into which the air flowed after leaving the compost container and being dehumidified. The oxygen concentration in the chamber $X_{c}$ is not equal to that at the exit of the container $X_{\text {ou }}$. Assuming perfect mixing conditions, the relationship between the two is given as follows:

$$
X_{\text {ou }}(t)=\Theta \frac{d X_{c}(t)}{d t}+X_{c}(t)
$$

where $\Theta\left(=V_{c} / v\right)$ represents a time constant, $v$ is the volumetric airflow rate through the compost mass by forced aeration, and $V_{c}$ indicates the chamber volume.

Oxygen concentration at the exit of the container $X_{\text {ou }}$ was estimated from Eq. (14). By substituting the value of $X_{\text {ou }}$ in Eq. (13), we obtained the value of $R_{X}$. $Q_{H}$ was then estimated by applying $R_{X}$ to Eq. (12). Figure 8 shows the obtained results of $Q_{H}$, which agreed well with the experimental results. In these calculations, the proportionality constant $a$ was set to $10000 \mathrm{~kJ} \mathrm{~kg}^{-1}$, that is, $30 \%$ less than $14000 \mathrm{~kJ} \mathrm{~kg}^{-1}$, the value given by Fujita (1993). One of the possible reasons for this result is that perfect aerobic conditions were not maintained. Another reason for the result may be the temporal variation in kinds of substrates and microbes. However, their time courses could not be obtained here. Therefore, these reasons could not be discussed in detail in this study. The relation between the value of $a$ and kinds of substrates and microbes remains to be solved.

Next, we consider the validity of the results by comparing the estimated heat generation rate with the value estimated from the measured degraded compost mass. Table 4 shows the mass of solid consumption corresponding to the mass of degraded organic matter and the values estimated by dividing the total amount of heat generation by the calorific value of the mixed compost materials. In this table, the former was estimated from the change in total mass and moisture content of the mixed compost materials between the initial and final stages. The calorific value, that is, the combustion heat of the mixed compost materials $\Delta H_{s}$, was $-22300 \mathrm{~kJ} \mathrm{~kg}^{-1}$, which was obtained in advance by using a bomb calorimeter (OSK100 OGAWA sampling). Both values for the mass of solid consumption shown in Table 4 agreed well with each other. 

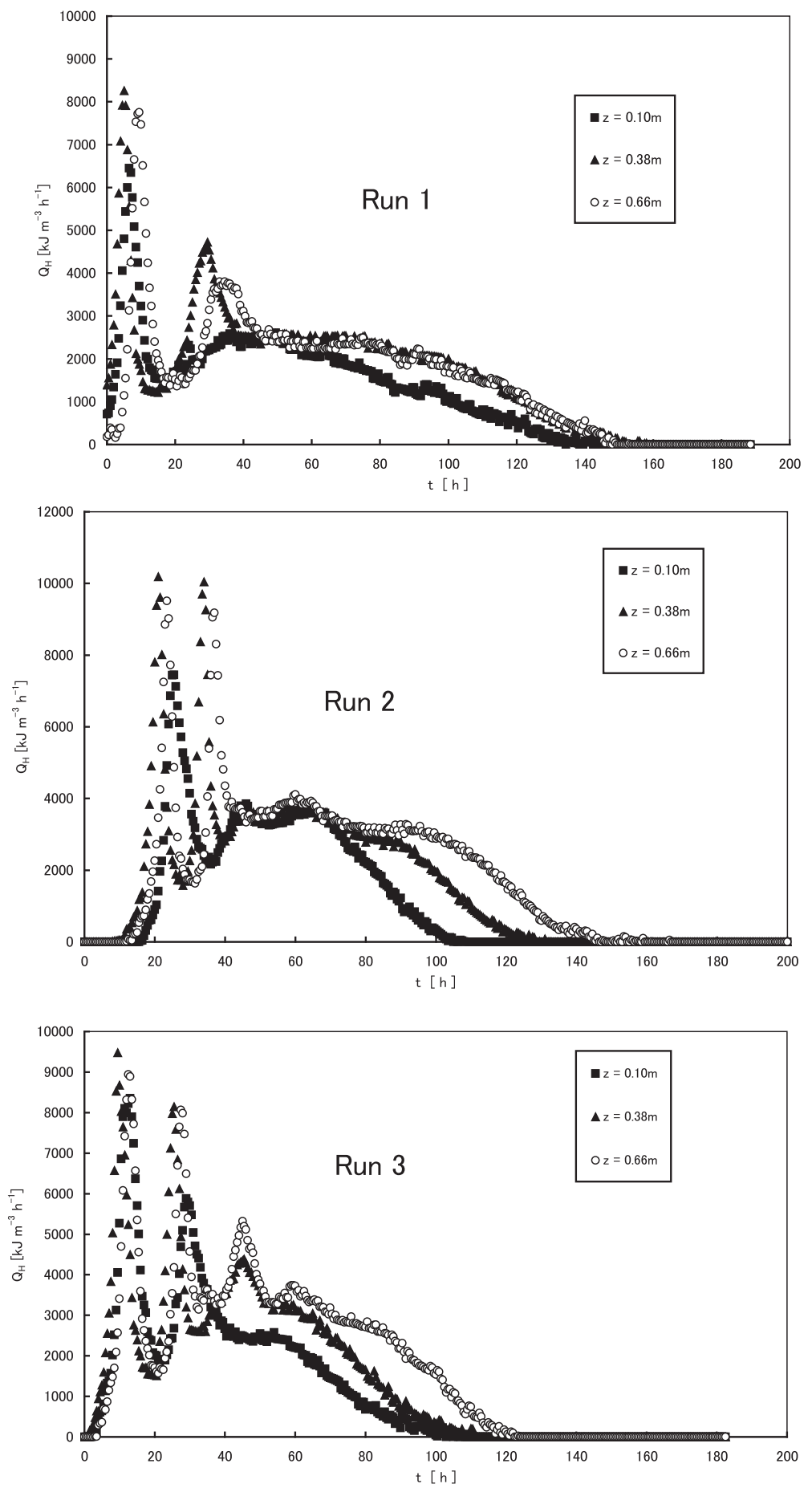

Fig. 7. Calculated $Q_{H}$ over time where the points $z=0.1,0.38$, and $0.66 \mathrm{~m}$ are representatives for the top, middle, and bottom region, respectively. 

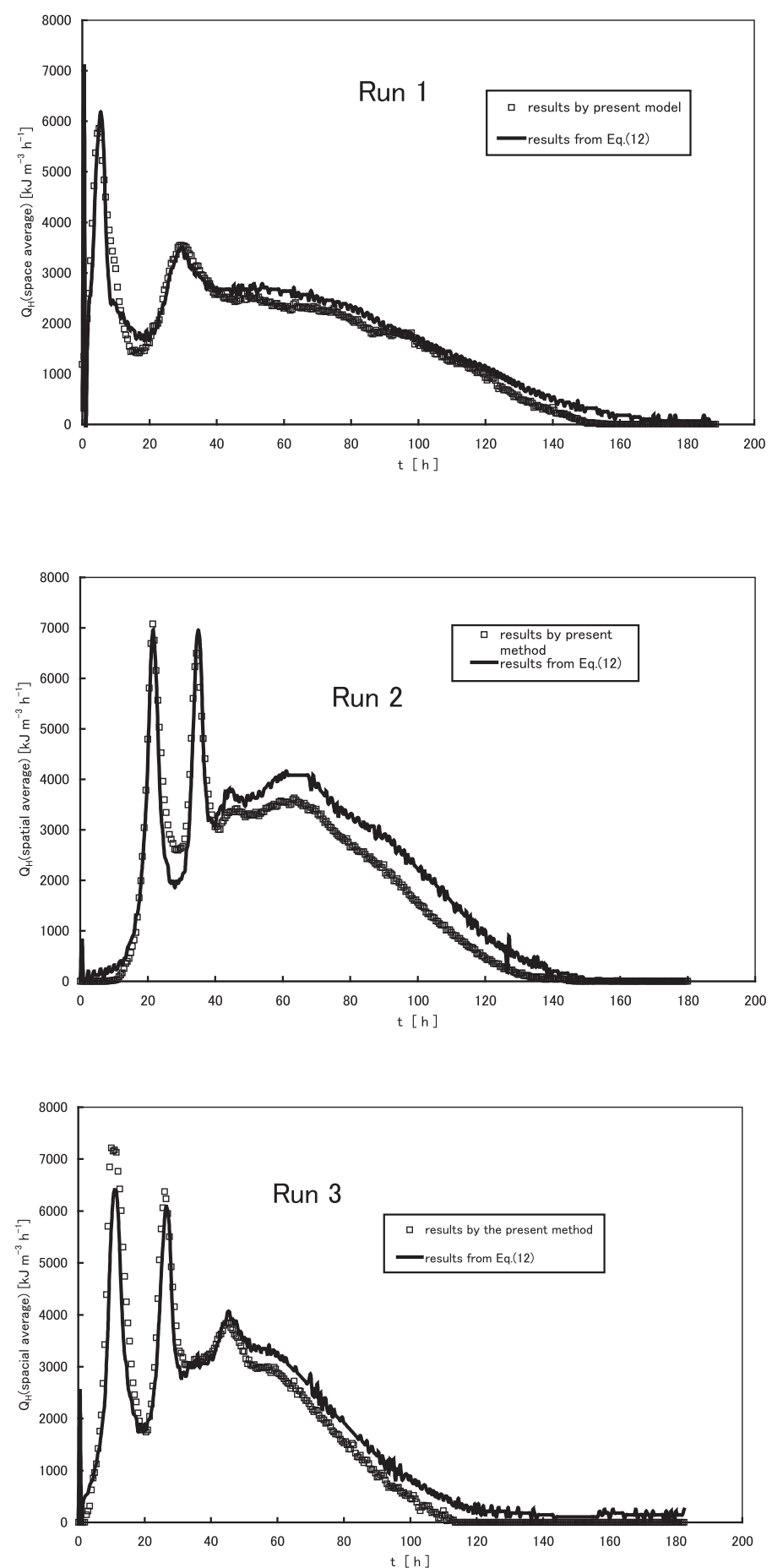

Fig. 8. Comparison of the spatial average value of $Q_{H}$ with the estimated results from oxygen consumption rate during composting. 
Table 4. Comparison of the experimental results of the mass of solid consumption with the estimated results from the total amount of heat generation.

\begin{tabular}{ccc}
\hline Run & $\begin{array}{c}\text { Experimental results of the mass } \\
\text { of solid consumption }[\mathrm{kg}]\end{array}$ & $\begin{array}{c}\text { Mass of solid consumption estimated } \\
\text { from the total amount of heat generation [kg] }\end{array}$ \\
\hline 1 & 0.305 & 0.284 \\
2 & 0.410 & 0.298 \\
3 & 0.298 & 0.266 \\
\hline
\end{tabular}

As the spatial average value of the heat generation rate obtained by the previously discussed method is acceptably accurate, the estimated results for the heat generation rate at any position of the container may also be valid.

\section{2) Characteristics of the obtained results}

According to Fig. 7, the heat generation rate did not vary spatially too much in the early stage, $0<t<30 \mathrm{~h}$ for run $1,0<t<60 \mathrm{~h}$ for run 2, and $0<t<40 \mathrm{~h}$ for run 3 , because there was no significant spatial variation of temperature. However, after the early stage, the heat generation rate varied in response to the temperature distribution along the height of the container. For example, in the upper region of the compost container, that is, at the air entrance, the heat generation rate was relatively small, since the temperature in this region was lower than that in the lower area. The heat generation rate then gradually decreased toward the end of the first stage of composting and approached almost zero at $t>150 \mathrm{~h}$.

Summarizing the above results, the following characteristics are shown:

a) An initial period of rapid increase in degradation rate.

b) A period of temperature shift from mesophilic and thermophilic stages.

c) An intermediate period of stable but slow heat generation.

d) A final period of decrease of heat generation rate after consumption of the substrate.

These characteristics are supposed to be related to the microbial shift according to temperature and substrate changes during decomposition. The basic features of time phases during the composting processes that are well known (Kubota and Hosono, 1977; Matsuzaki, 1992) are as follows.

In the early stage, easily degradable substrates, such as carbohydrate, protein, and fat, decompose. In the intermediate stage, after the early stage, degradable materials such as hemicelluloses and cellulose start to decompose under coexisting aerobic and anaerobic conditions. The degradation rate gradually decreases with decreasing amounts of these degradable materials.

The above explanation could be qualitatively applicable to the characteristics given in this study. However, a detailed explanation concerning the changes in the heat generation rate corresponding to the reaction rate will be required after measuring the nutritional information. Moreover, it is advisable to quantitatively examine the relationship between the changes in the heat generation rate and in the substrate.

\section{Summary}

We proposed a practical method for estimating the heat generation rate in the composting process under a forced aeration condition without using highly technical measurements. This method applies the measured temperature to the balance equations of heat and moisture. The heat generation rates estimated using this method agreed well with the results estimated from the oxygen consumption rates, and the amount of biologically decomposed organic matter also corresponded closely with the measured results. Therefore, the validity of this method has been confirmed. This experiment was conducted using only rice bran as the principal material; however, it is necessary to conduct experiments for other types of material and confirm whether the proposed method can be applied to estimate the composting reaction rate by using the heat balance equations, irrespective of the type of organic component.

It is also necessary to develop a quantitative model of the reaction rate relating to the dynamic analysis of microbes and substrates in order to support system design for process control.

\section{References}

Atkins, P., and de Paula, J., 2006: Atkins' Physical Chemistry (8th edition). Oxford Univ. Press, New York, p. 212. 
Bear, J., and Bachmat, Y., 1991: Introduction to Modeling of Transport Phenomena in Porous Media. Kluwer Academic Publishers, Dordrecht, Netherland, 553 pp.

Das, K., and Keener, H. M., 1997: Numerical Model for the Dynamic Simulation of a Large-Scale Composting System. Trans. ASAE, 40 (4), 1179-1189.

Finger, S. M., Hatch, R. T., and Regan, T. M., 1976: Aerobic Microbial Growth in Semisolid Matrices: Heat and Mass Transfer Limitation. Biotechnol. Bioeng., 18, 1193-1218.

Fujita, K., 1993: Composting technology. Gihodo shuppan, Tokyo, 196 pp. (in Japanese).

Himmelblau, D. M., and Bischoff, K. B., 1968: Process Analysis and Simulation: Deterministic Systems, John Wiley \& Sons, New York, pp. 27-28.

Inoue, T., 2003: Reaction analysis. Chap. 3. In Composting of Biomass Resources (ed. by Kimura, T.). CMC Publishers, Tokyo, pp. 53-64.

Iwabuchi, K., and Kimura, T., 1994: Aerobic biodegradation of dairy cattle feces Part 1: heat production rate and oxygen uptake rate. Nougyoukikaigakkaishi, 56 (2) , 67-74 (in Japanese with English abstract).

Izawa, T., 1989: Composting. Chap. 2.1.5. In Biomass Handbook (ed. by Kitani, O., and Hall, C. W.). Gordon and Breach Science Publishers, New York, pp. 302-306.

Kaiser, J., 1996: Modeling composting as a microbial ecosystem: a simulation approach. Ecol. Model., 91, 25-37.

Kimura, T., 2003: Introduction. Chap. 1. In Composting of Biomass Resources (ed. by Kimura, T.). CMC Publishers, Tokyo, pp. 3-4.

Kubota, H., and Hosono, Y., 1977: Composting. Kagakukogaku, 41 (7), 364-368 (in Japanese) .

Matsuzaki, T., 1992: Soil, Compost, and Organic Materials. Ienohikari-kyokai, Tokyo, pp. 47-54 (in Japanese).

Nakasaki, K., Kato, J., Akiyama, T., and Kubota, H.,
1987: A new composting model and assessment of optimum operation for effective drying of composting material. J. Ferment. Technol., 65 (4) , 441-447.

Seki, H., 2002: A new deterministic model for forcedaeration composting processes with batch operation. Trans. ASAE, 45 (4), 1239-1250.

Seki, H., and Komori, T., 1983: Heat transfer in composting process. J. Agric. Meteorol., 39(3), 173179 (in Japanese with English summary).

Seki, H., and Komori, T., 1984: Heat transfer in composting process (Part 2). J. Agric. Meteorol., 40 (1), 37-45 (in Japanese with English summary).

Seki, H., Asai, N., and Higashi, K., 2008: Equipment of composting for educating waste treatment and effective resource utilization. Proc. Annu. Meet. Soc. Agric. Meteorol. Jpn., 69 (in Japanese).

Stombaugh, D. P., and Nokes, S. E., 1996: Development of a biologically based aerobic composting simulation model. Trans. ASAE., 39 (1) , 239-250.

Tang, J.-C., Shibata, A., Zhou, Q., and Katayama, A., 2007: Effect of temperature on reaction rate and microbial community in composting of cattle manure with rice straw. J. Biosci. Bioengi., 104(4), 321328.

Uematsu, K., Hashimoto, H., Waiuchi, T., and Wada, E., 1982: Butsurikagakuyousetsu, Tokyo Kyougakusha, Tokyo, 372 pp. (in Japanese).

VanderGheynst, J. S., Walker, L. P., and Parlange, J., 1997: Energy transport in a high-solids aerobic degradation process: mathematical modeling and analysis. Biotechnol. Prog., 13, 238-248.

Wakase, S., Sasaki, H., Itoh, K., Otawa, K., Kitazume, O., Nonaka, J., Satoh, M., Sasaki, T, and Nakai, Y., 2008: Investigation of the microbial community in a microbiological additive used in a manure composting process. Bioresour. Technol., 99, 2687-2693.

Yukishitsusigenka-suishinkaigi, 1997: Yukihaikibutsushigenkadaijiten. Nosangyosonbunkakyokai, Tokyo, 511 pp. (in Japanese). 